\title{
IMPLEMENTASI METODE MAQASHID SYARIAH IMAM AL SYATHIBI PADA PRAKTIK PERBANKAN SYARIAH DI INDONESIA
}

\section{IMPLEMENTATION OF IMAM AL SYATHIBI SHARIA MAQASHID METHODS IN ISLAMIC BANKING PRACTICES IN INDONESIA}

\author{
Lasri Nijal ${ }^{\mathbf{1}}$,Putri Apria Ningsih ${ }^{\mathbf{2}}$ \\ Program Studi Sistem Informasi Universitas Lancang Kuning ${ }^{1}$ \\ Program Studi Universitas Islam Negeri Sulthan Thaha Saifuddin Jambi ${ }^{2}$ \\ lasrinijal@gmail.com ${ }^{1}$
}

Submit, 03-10-2018 Accepted, 28-12-2018 Publish,03-02-2019

\begin{abstract}
Only with the Maqashid Syari'ah approach that Islamic banking and financial products can develop well and can respond to the progress of business that continues to change rapidly. Imam Al-Syatibi was dubbed the father of Maqashid Sharia because of the results of his work which had systematized Maqashid al-Shari'ah into a new methodology that produced ijtihady jurisprudence or Maqashidy figh. In the context of Sharia business practices, the achievement of Maqashids Shariah can be measured through the achievement of goals in the form of individual education or knowledge, creation of justice and achievement of public interests. Sharia banks must ensure fair transactions in all business activities, including products, prices and the time period in the contract and its conditions. Islamic banks must also ensure that all business ventures that are free from negative elements can cause injustice, such as usury (including interest), fraud, corruption, etc.
\end{abstract}

Keywords: Maqashid, Al Syathibi, Islamic Banking

ABSTRAK
Hanya dengan pendekatan Maqashid Syari'ah-lah produk perbankan dan keuangan syariah dapat berkembang dengan baik dan dapat merespon kemajuan bisnis yang terus berubah dengan cepat. Imam Al-Syatibi digelari bapak maqashid syariah karena hasil kerja beliau yang telah mensistematisasikan maqashid al-syari'ah menjadi sebuah metodologi baru yang menghasilkan fiqih ijtihady atau fiqih maqashidy. Dalam konteks praktik bisnis Syariah, pencapaian Maqashids Shariah dapat diukur melalui pencapaian tujuan berupa pendidikan individu atau harus berilmu, penciptaan keadilan dan pencapaian kepentingan publik. bank Syariah harus memastikan transaksi wajar dalam semua kegiatan bisnis, yang meliputi produk, harga dan jangka waktu dalam kontrak dan kondisinya. Bank Syariah juga harus memastikan bahwa semua usaha bisnis yang bebas dari unsur-unsur negatif dapat menimbulkan ketidakadilan, seperti riba (termasuk bunga), penipuan atau kecurangan, korupsi, dan lain sebagainya.

Kata Kunci : Maqashid, Al Syathibi, Perbankan Syariah

\section{PENDAHULUAN}

Tujuan utama dari sistem perbankan syari'ah adalah untuk mencapai dan mewujudkan kesejahteraan umat secara luas dunia dan akhirat. Dengan mengacu pada tujuan utama ini, maka Maqashid Syari'ah menjadi sandaran utama dalam setiap pengembangan operasional dan produkproduk yang ada pada bank syariah. Maqashid Syari'ah akan memberikan pola pemikiran yang rasional dan substansial dalam memandang akadakad dan produk-produk perbankan syariah. Hanya dengan pendekatan Maqashid Syari'ah -lah produk 
perbankan dan keuangan syariah dapat berkembang dengan baik dan dapat merespon kemajuan bisnis yang terus berubah dengan cepat (Muhammad Zaki 2015). Awal kemunculan istilah maqashid al-syari'ah belumlah diketahui secara pasti, akan tetapi penggunaan istilah ini sudah lama digunakan dalam tradisi ulama fiqh. Sampai akhirnya datang ulama besar yang diberi predikat sebagai bapak maqashid al-syari'ah yaitunya Imam AlSyatibi, beliau digelari bapak maqashid syariah karena hasil kerja beliau yang telah mensistematisasikan maqashid alsyari'ah menjadi sebuah metodologi baru yang menghasilkan fiqih ijtihady atau fiqih maqashidy.

Imam Asy-Syathibi telah mengungkapkan tujuan syari'ah dan fungsinya bagi manusia, hal ini seperti ungkapannya yang bisa kita lihat dalam kitab al-Muwwafaqat: "Sesungguhnya syariat itu ditetapkan bertujuan untuk tegaknya (mewujudkan) kemashlahatan manusia di dunia dan Akhirat". Pada bagian lainnya beliau menyebutkan: "Hukum-hukum diundangkan untuk kemashlahatan hamba." Dengan kata lain, tujuan hukum Islam menurut Imam Al Syathibi adalah kemaslahatan hidup bagi manusia, baik rohani maupun jasmani, individual ataupun sosial. Kemaslahatan itu tidak hanya untuk kehidupan dunia ini saja tetapi juga untuk kehidupan yang kekal di akhirat kelak.

Untuk itu penulis merasa sangat perlu untuk melihat sejauh mana implementasi maqashid syari'ah Imam As Syathibi pada perbankan syariah di Indonesia kemudian mengusulkan solusi terhadap permasalahan syari'ah dari perbankan syariah sesuai dengan metode maqashid syari'ahnya Imam As Syathibi. Mengingat semakin tumbuh suburnya kemajuan perbankan syari'ah di Indonesia bersamaan dengan semakin konplitnya permasalahan yang dihadapi, agar setiap solusi yang diberikan tidak keluar dari jalur syariah walaupun dengan beralasan maqashid syariah atau alasan lainnya yang tidak bisa diterima.

\section{METODE PENELITIAN}

Penelitian ini merupakan penelitian perpustakaan (library research). Yaitu dengan mendalami ide-ide Imam Al Syathibi tentang maqashid syariah yang beliu tuangkan dalam kitabnya yang sangat fenomenal yaitu "Al Waraqath fi ushulissyariah". Setelah penulis temukan ide atau pendapat Imam Al Syathibi tentang maqashid syariah seterusnya penulis mengkorelasikannya dengan perkembangan perbankan syari'ah di tanah air dimasa modern ini. Sehingga metode khas maqashid syariah Imam Al Syathibi yang terkenal sebagai bapak maqashid syariah mampu menjawab setiap persoalan baru perbankan syariah di tanah air dari kacamata syariah islamiyah.

\section{Kerangka Pemikiran \\ Imam Al-Syathibi}

Imam

Al-Syatibi bernama

lengkap Ibrahim bin Musa bin Muhammad, dengan sapaan kondangnya Abu Ishak, beliau merupakan keturunan dari Banu Lakhm, keturunan ArabYaman dari Banu Lakhm yang berasal dari Betlehem, Asy-Syam (Abdul karim bin Muhammad bin Manshur As Sam'ani 1382 H, 1962 M). Ada juga yang mengatakan bahwa kata lakhmu berasal dari yaman, terpakai oleh salah satu nama penguasa pada zaman jahiliyyah, diantaranya Al amru bin adiy bin nasir al lakhmi (Al Jauhary). Tempat dan tanggal lahir 
Imam Al Syatibi tidak diketahui secara pasti, namun nama Al-Syatibi sering dihubungkan dengan nama sebuah tempat di Spanyol bagian timur Andalus, yaitu Sativa atau Syatiba (Arab), yang asumsinya al-Syatibi lahir atau minimal pernah tinggal di sana. Daerah ini cukup terkenal pada masa akhir kejayaan Islam di Spanyol. Banyak ulama ternama lain yang lahir dari daerah ini (Syihabuddin Abi Abdillah Yaqut bin Abdillah Al Hamawi Ar Rumi, 1977 M, 1397 H).

Pemikiran Dan Maqashid Syariah Imam Al-Syathibi

Pada dasarnya seluruh aturan hukum (syariat Islam) bertujuan untuk mewujudkan kemaslahatan manusia yaitu pemeliharaan agama (hifz din), jiwa (hifz nafs), keturunan (hifz nasl), harta (hifz mal), dan akal (hifz aql) (La Jamaa, 2011). Ciri khas Metode maqashid al-syariah Imam Al-Syathibi dapat kita jelaskan sebagai berikut (Dr. Abdur Razaq Waraqyah, 2007):

1. Dasar ilmu maqashid Imam Al Syathibi sama dengan ulama-ulama sebelumnya.

Dalam menyelami luasnya lautan maqashid syariah Imam Al Syathibi tidak keluar dari dasar-dasar ilmu maqashid yang telah menjadi kesepakan ulama-ulama terdahulunya, semua mereka selalu masuk kepada pembahasan maqashid dari pintu yang sama. Yaitu memahami terlebih dahulu At Ta'lil, Al Qashdu, Al Iradah, kemudian At-Taqbih dan At-tahsin.

\section{Suatu ilmu haruslah direalisasikan} dalam perbuatan

Bagian ini merupakan hasil observasi dari pernyataan-pernyataan imam Al Syathibi dalam tulisannya, seperti: a. Berilmu tanpa diamalkan maka sangatlah tercela secara syariat.

Hal ini seperti yang beliau ungkapkan dalam muqaddimah ke-5 dalam kitab Al Muwafaqatnya: "mendalami setiap masalah yang tidak didasarkan pada syariat bearti pendalaman yang tidak ada kebaikannya menurut syariat", bahwa Pembuat Syariat menolak segala sesuatu yang tidak ada hubungannya dengan amalan makallaf bih" (Abu Ishaq as Syatibi, 2006). Silakan perhatikan jawabanjawaban yang diberikan Rasulullah SAW terhadap pertanyaan-pertanyaan yang diajukan para sahabat kepadanya. Jawaban tersebut selalu berhubungan dengan amalan dan tidak harus mengikuti semua yang diinginkan oleh sahabat yang bertanya. Seperti pertanyaan tentang Ahillah (bulan sabit), tentang hari kiamat, tentang Ruh dan lain sebagainya, langsung dijawab oleh Allah melalui firmanNya kepada Rasulullah SAW dengan jawaban yang berhungan dengan amalan.

b. Amalan yang dikerjakan bertujuan ibadah kepada Allah SWT

Sebagaimana yang beliau sebutkan pada Muqaddimah ke-7: "setiap ilmu syar'I yang diperintahkan oleh Allah SWT untuk dikerjakan adalah sebagai perantara beribadah kepadaNya bukanlah untuk hal yang lain" (Abu Ishaq as Syatibi, 2006).

c. Amalan menjadi cerminan akan ketinggian ilmu para ulama

Imam Al Syathibi membuat tiga syarat dari ketinggian ilmu para ulama: pertama; mengamalkan yang diketahuinya, apabila syarat ini gugur maka gugur juga kedudukan ulama yang bersangkutan. Kedua; ilmu para ulama tersebut haruslah mereka dapatkan dari 
pengajaran syuyukh atau guru-guru mereka dengan cara mulazamah dan yang ketiga adalah; meneladani dengan penuh adab para ulama atau guru yang telah mengajarkan ilmu tersebut, sebagaimana para sahabat Rasulullah SAW telah mencontoh Rasulullah SAW sesuai dengan yang mereka lihat dan saksikan dari rasulullah (Abu Ishaq as Syatibi, 2006).

3. Kesesuaian Amalan dengan maqashid syar'iyyah

Dengan meneliti kitab muwafaqat penulis menemukan empat tingkatan maqashid yang mana haruslah setiap amalan sesuai dengannya:

a. Tingkatan pemula

Level pemula ini merupakan tujuan utama dari maqashid syariah, dimana dia terbagi kepada tiga bagian yaitu: Dharuriyat, Hajiyat dan Tahsiniyat.

Kebutuhan dharuriyat ialah tingkat kebutuhan yang harus ada, atau disebut juga dengan kebutuhan primer. Bila tingkat kebutuhan ini tidak terpenuhi, akan terancamlah keselamatan umat manusia baik di dunia maupun di akhirat kelak. Menurut Imam al-Syatibi ada lima hal yang termasuk dalam kategori ini, yaitu memelihara agama, memelihara jiwa, memelihara akal, memelihara kehormatan dan keturunan, serta memelihara harta. Untuk memelihara lima pokok inilah Syariat Islam diturunkan. Setiap ayat hukum bila diteliti akan ditemukan alasan pembentukannya yang tidak lain adalah untuk memelihara lima pokok diatas.

Kebutuhan hajiyat ialah kebutuhan sekunder, bilamana tidak terwujudkan maka tidaklah sampai mengancam keselamatan, namun tetap akan mengalami kesulitan. Syariat Islam menghilangkan segala kesulitan itu. Adanya hukum rukhshah (keringanan) adalah sebagai contoh dari kepedulian Syariat Islam terhadap kebutuhan ini.

Dalam lapangan ibadat, Islam mensyariatkan beberapa hukum rukhshah (keringanan) bilamana kenyataannya mendapat kesulitan dalam menjalankan perintah-perintah taklif. Misalnya, Islam membolehkan tidak berpuasa bilamana dalam perjalanan dalam jarak tertentu dengan syarat diganti pada hari yang lain dan demikian juga halnya dengan orang yang sedang sakit. Kebolehan meng-qasar shalat adalah dalam rangka memenuhi kebutuhan hajiyat ini.

Kebutuhan tahsiniyat ialah tingkat kebutuhan yang apabila tidak terpenuhi tidaklah akan mengancam eksistensi salah satu dari lima pokok di atas, dan tidak pula menimbulkan kesulitan. Tingkat kebutuhan ini berupa kebutuhan pelengkap, seperti dikemukakan Imam al-Syatibi, hal-hal yang merupakan kepatutan menurut adat istiadat, menghindarkan hal-hal yang tidak enak dipandang mata, dan berhias dengan keindahan yang sesuai dengan tuntutan moral dan akhlak.

b. Tingkatan kepahaman

Seorang Mujtahid sebelum merealisasikan sebuah hukum kedalam perbuatan atau dunia real, haruslah terlebih dahulu mengetahui bahwa syariah beserta maqashidnya bersifat umum bagi seluruh mukallaf. Untuk itu perlu dipahami oleh seorang mujtahid terlebih dahulu harusnya memiliki kemampuan yang matang terhadap bahasa Arab, karena syariat diturunkan dengan bahasa Arab. Selanjtnya karena Syariat itu bersifat ummiyah (tidak bisa 
tulis baca) syariat diturunkan untuk manusia secara umum, diantara mereka ada orang terdidik dan ada pula yang tidak mengerti tulisan dan bacaan, untuk itu syariat memiliki standar yang bisa dipahami oleh semua orang baik orang terdidik maupun yang tidak bisa tulis baca. Dalam memahamkan syariat ini seorang mujtahid haruslah mampu memahamkan kepada seluruh level manusia itu termasuk kepada kaum ummy (tidak bisa tulis baca).

c. Tingkatan taklif (tanggung jawab)

Hukum yang Allah turunkan merupakan taklif (tanggung jawab) bagi manusia, untuk itu perlulah kiranya merincikan syarat-syarat terjadinya taklif bagi umat. Diantara syarat itu adalah harus adanya qudrah (kemampuan mukallaf), sehingga ketika seorang mukallaf tidak mempunyai kesanggupan maka tidaklah mereka dituntut tanggung jawabnya untuk melaksanakan.

d. Tingkatan ta'at

Setelah syarat-syarat taklif terpenuhi oleh seorang hamba (Mukallaf) barulah naik ke tingkat selanjutnya yaitu kewajiban mentaati dan melaksanakan semua hukum Allah SWT. Sebagaimana yang dikatakan oleh Imam Al Syathibi: "tujuan adanya syariat adalah mengeluarkan manusia dari hawa nafsu menuju penghambaan diri kepada Allah SWT baik atas kesadaran dan pilihan mereka sendiri ataupun karena keterpaksaan (Abu Ishaq as Syatibi, 2006).

Dengan memahami penjelasan di

atas dapat kita simpulkan bahwa kemashlahatan menurut Imam al-Syatibi dilihat dari dua sudut pandang, yaitu (1) maqasid al-syari' (tujuan Tuhan), dan (2) maqasid al-mukallaf (tujuan mukallaf) (La Jamaa, 2011). Maqasid al- syari'ah dalam arti maqasid al-Syari', mengandung empat aspek, yaitu:

a. Tujuan awal dari syariat, yakni kemaslahatan manusia di dunia dan di khirat.

b. Syariat sebagai sesuatu yang harus dipahami.

c. Syariat sebagai suatu hukum taklif yang harus dilakukan

d. Tujuan syariat adalah membawa manusia ke bawah naungan hukum (Abu Ishaq as Syatibi, 2006).

Di dalam bukunya $\mathrm{Al}$ Muwafaqot, Imam Al Syatibi telah membuka lebar-lebar peluang bagi ulama-ulama syari'ah untuk terus menggali rahasia-rahasia Syari'at Islam ini secara lebih luas. Barangkali cukup apa yang dikatakan Syeikh Muhammad Fadhil ibnu Asyura: "Sesungguhnya Imam Syatibi di dalam bukunya Muwafaqot, telah mampu membangun proyek raksasa di dalam Tsaqofah Islamiyah, darinya kita mampu melihat cara-cara untuk menjaga agama ini, yang belum disadari oleh sebagian besar orang-orang sebelum Imam Syatibi. Sehingga ulama-ulama yang konsen dalam penggalian rahasia-rahasia syari'at setelahnya bisa dikatagorikan sebagai pengikutnya, Mulai nampak kelebihan bukunya pada saat ini dengan keadaan yang menakjubkan, ketika dunia Islam pada masa kebangkitan dihadapkan pada problematika penyelarasan antara hukum syari'at dengan perkembangan zaman, maka buku muwafaqot hadir untuk memberikan jawabannya.

\section{HASIL DAN PEMBAHASAN \\ Problematika Perbankan Syariah Di Indonesia}

Terdapat tujuh masalah yang menjadi tantangan dan perlu diatasi oleh 
perbankan syariah agar dapat maju dan berkembang (Tempo.co 2018).

Pertama, kurangnya sinergi antara Otoritas Jasa Keuangan (OJK) dan pemerintah dalam membangun industri keuangan syariah. Kedua, permasalahan modal perbankan syariah. Dari total 12 bank syariah saat ini, 6 bank masih berada di kategori Bank Umum Kegiatan Usaha (BUKU) 1 atau permodalan kurang dari Rp 1 triliun, dan 6 bank lain berada di kategori BUKU 2 atau permodalan antara $\mathrm{Rp}$ 1-5 triliun. ketiga biaya dana perbankan syariah yang mahal. Hal ini menjadi penyebab masyarakat mengeluh perbankan syariah lebih mahal dibandingkan bank umum konvensional. keempat adalah produk bank syariah yang tidak variatif dan belum dapat diakses masyarakat. kelima adalah terkait dengan kualitas sumber daya manusia di perbankan syariah yang kurang memadai. keenam adalah terkait dengan pemahaman dan kesadaran masyarakat tentang perbankan syariah yang masih kurang. Dan terakhir adalah terkait dengan pengaturan dan pengawasan perbankan syariah oleh OJK yang masih harus ditingkatkan.

Menurut beberapa jurnal bahwa permasalahan dalam hal pengembangan perbankan syariah di Indonesia dapat dibagi menjadi 4 aspek yang terdiri dari aspek sumber daya manusia (SDM),Teknikal, Legal/Struktural dan aspek Pasar/Komunal (Aam Slamet Rusyidiana, 2016).

Aspek Sumber Daya Manusia (SDM) pertama; lemahnya pemahaman praktisi bank syariah, baik sisi pengembangan bisnis maupun sisi syariah. Dengan kata lain belum terpenuhinya sumber daya insani yang mumpuni di bidang ekonomi syariah, sehingga dalam praktiknya perbankan syariah seringkali menyimpang dari prinsip syari'ah. Kedua, supply oriented. Praktisi hanya bisa menjelaskan apa yang mereka tahu tetapi tidak bisa menjawab apa yang ditanyakan oleh masyarakat. Ketiga, belum memadainya sumber daya manusia yang terdidik dan profesional, terutama teknis manajerial.

Aspek Technical, pertama, permodalan (dana) bank syariah masih belum memadai dan biaya dana yang mahal yang berdampak pada keterbatasan segmen pembiayaan. Dampaknya, secara umum bank syariah tidak se-efisien bank konvensional. Kedua, inovasi di bidang produk dan layanan, pemasaran dan pengembangan bisnis yang dimiliki bank syariah masih lemah,Ketiga, kurang memadainya fasilitas atau infrastruktur teknologi informasi (IT), padahal hal tersebut merupakan prasyarat penting keberhasilan lembaga keuangan.

Aspek Legal/Struktural pertama, belum selarasnya visi dan kurangnya koordinasi antar pemerintah dan otoritas dalam pengembangan perbankan syariah. Kedua, pengaturan dan pengawasan yang masih belum optimal. Ketiga,Kurangnya support dan dukungan pemerintah terhadap pengembangan perbankan syariah, terutama jika dibandingkan dengan negeri Jiran.

Aspek Pasar/Komunal, pertama; salah satu permasalahan yang masuk dalam bagian ini adalah masalah persaingan, baik persaingan antar bank syariah sendiri maupun dengan lembaga keuangan lainnya. Kedua; masalah pada tingkat kepercayaan, adalah kurangnya minat masyarakat dalam menyimpan dana di bank syariah karena rasa tidak 
percaya kepada bank syariah atau karena return yang rendah di banding bank konvensional. Ketiga; kurangnya pengetahuan masyarakat terhadap keberadaan bank syariah, baik dari sisi pelayanan yang diberikan, maupun pengetahuan akad yang relatif lebih "rumit".

Isu kritis terkait produk bank syariah adalah isu klasik dominasi murabahah dalam pembiayaan. Murabahah memang bukan transaksi yang dilarang, tetapi seharusnya akad ini menjadi akad sekunder karena bank syariah idealnya lebih banyak menggunakan akad bagi hasil. Tetapi isu ini tentu, bukan karena keengganan bank syariah saja, tetapi juga disebabkan oleh paradigma masyarakat atau nasabah yang juga belum siap dengan akad bagi hasil. Nasabah penabung belum siap dengan fluktuasi bagi hasil murni terhadap tabungan atau deposito mereka. Faktor tingkat bagi hasil masih menjadi prioritas pilihan nasabah untuk menabung di bank syariah. Sehingga ketidaksiapann ini juga ikut memaksa bank syariah untuk memperoleh return secara tetap dan murabahah adalah diantara pilihannya disamping prosedur dan risiko yang minim (Sepky Mardian, 2015).

Selanjutnya perataan laba atau income smoothing adalah diantara isu yang terkait dengan laporan keuangan di bank syariah. Seperti dijelaskan sebelumnya karena nasabah belum siap dengan fluktuasi bagi hasil murni, maka ini memberikan insentif kepada bank syariah untuk melakukan perataan laba atau bagi hasil yang diperoleh di periode tertentu dengan mencadangkannya dan mengeluarkan cadangan tersebut pada kondisi lain saat bagi hasil turun.
Kebijakan ini bisa menimbulkan penzaliman terhadap beberapa nasabah karena haknya atas bagi hasil tidak ditunaikan sebagaimana seharusnya. Namun, kebijakan ini telah mendapatkan fatwa dari DSN-MUI yang membolehkan kebijakan tersebut dengan syarat bank meminta persetujuan dengan nasabah yang hak tidak ditunaikan sebagaimana seharusnya (Sepky Mardian, 2015).

Implementasi Maqashid Syariah Imam Al Syathibi Sebagai Solusi Permasalahan Perbankan Syariah Di Indonesia

Bank Syariah harus memiliki tujuan yang jauh lebih besar dibandingkan hanya untuk mencapai laba maksimum dan juga harus berusaha untuk mewujudkan Maqashid Shariah. Agar dapat mencapai Maqashid Shariah, sebuah lembaga bisnis Syariah harus mampu melakukan penjagaan pada alaql (pikiran), addien (agama), nafs (jiwa), nasl (keturunan), maal (harta). Dalam konteks praktik bisnis Syariah, pencapaian Maqashids Shariah dapat diukur melalui pencapaian tujuan berupa pendidikan individu, penciptaan keadilan dan pencapaian kepentingan publik (Jumansyah, Ade Wirman Syafei, 2013).

Dalam mencapai Maqashid Shariah tersebut, pengelolaan bank Syariah harus mengacu kepada standard dan pedoman tata kelola yang sesuai dengan prinisp-prinsip Syariah. Bank Indonesia mendorong agar pengelolaan bank Syariah di Indonesia mengacu kepada prinsip-prinsip Good Governance Bisnis Syariah (GGBS). Bank Indonesia juga mengharapkan dengan pengelolaan bank Syariah berdasarkan kepada prinsip-prinsip 
GGBS maka akan mendorong terwujudnya bank Syariah yang sehat secara financial namun juga bank Syariah yang patuh terhadap prinispprinsip Syariah dalam seluruh lini operasionalnya (Jumansyah, Ade Wirman Syafei, 2013).

Berdasarkan prinsip mashlahah yang dikemukakan oleh Imam As Syathibi yaitu harus dalam rangka menegakkan keadilan maka bank syariah harus memastikan transaksi wajar dalam semua kegiatan bisnis, yang meliputi produk, harga dan jangka waktu dalam kontrak dan kondisinya. Bank Syariah juga harus memastikan bahwa semua usaha bisnis yang bebas dari unsur-unsur negatif dapat menimbulkan ketidakadilan, seperti riba (termasuk bunga), penipuan atau kecurangan, korupsi, dan lain sebagainya. Secara tidak langsung, Bank Syariah harus bijak dalam menggunakan keuntungannya dan mengarahkan kegiatan-kegiatannya kearah yang penting, yang dapat membantu mengurangi pendapatan dan kesenjangan sosial, serta dapat memutarkan harta dan pembagian bagi hasil secara adil. Bank Syariah harus bisa memberikan prioritas untuk kegiatan bisnis yang menghasilkan manfaat yang lebih besar kepada masyarakat. Kegiatan ini termasuk dibidang yang berkaitan dengan kebutuhan dasar masyarakat seperti investasi pada sektor-sektor penting dan pembiayaan proyek perumahan.

Berdasarkan nilai maghashid syariah Imam Al Syathibi yang ke-2 dan ke-3, bahwasanya haruslah berilmu dan ilmu itu harus di aplikasikan dalam dunia real maka haruslah ada penyebaran pengetahuan dan keterampilan serta menanamkannya kedalam nilai-nilai individu untuk perkembangan spiritualnya. Dengan demikian, Bank Syariah harus merancang program-program pendidikan dan pelatihan yang harus dapat mengembangkan tenaga kerja berpengetahuan dan terampil serta memiliki nilai-nilai moral yang tepat. Selain itu Bank Syariah juga harus memberikan informasi tentang produkproduk mereka kepada para pemegang saham.

Bank-bank syariah dikonsep sebagai lembaga keuangan, dimana keseluruhan pinjaman bisnis yang diberlakukan kepada pengusaha (nasabah) berdasarkan prinsip bagi hasil (profit and loss sharing). Dengan demikian bagi hasil seharusnya merupakan mekanisme yang dominan di bank syariah, namun kenyataannya mekanisme produk bagi hasil tidak menunjukkan prosentase yang cukup tinggi (Abdullah Saeed, 2003).

Pada akad mudharabah di perbankan syariah dikenal apa yang disebut "dua tahap" atau two-tier" mudharabah. Hal ini karena perbankan syariah merupakan lembaga "perantara" atau "intermediaries" sebagai dasar peghimpunan dana masyarakat untuk disalurkan kembali kepada masyarakat dalam berbagai pembaiayaan dan penyertaan modal.

\section{PENUTUP}

\section{Kesimpulan}

Masalah baru dalam dunia
perekonomian tidak akan pernah
habisnya, apalagi ketika membicarakan
tentang perbankan syariah, karena
keberadaan perbankan syariah masih
dianggab baru sehingga masih terjadi
ketimpangan disana-sini.


Imam as Syathibi dalam buku Al Muwafaqatnya telah memberikan jalan keluar untuk permasalahanpermasalahan baru yang akan dihadapi oleh umat muslim dimasa yang akan datang.

Dari sudut pandang maqashid syariah yaitu prinsip mashlahah dari Imam As Syathibi solusi dari bnyak permasalahan baru itu adalah:

1. Harus dalam rangka menegakkan keadilan. Untuk itu bank Syariah harus memastikan transaksi wajar dalam semua kegiatan bisnis.

2. Bank Syariah juga harus memastikan bahwa semua usaha bisnis bebas dari unsur-unsur negatif dapat menimbulkan ketidakadilan, seperti riba (termasuk bunga), penipuan atau kecurangan, korupsi, dan lain sebagainya.

3. Bank Syariah harus bijak dalam menggunakan keuntungannya dan mengarahkan kegiatan-kegiatannya kearah yang penting, serta dapat memutarkan harta dan pembagian bagi hasil secara adil.

4. Bank Syariah harus bisa memberikan prioritas untuk kegiatan bisnis yang menghasilkan manfaat yang lebih besar kepada masyarakat. Kegiatan ini termasuk dibidang yang berkaitan dengan kebutuhan dasar masyarakat seperti investasi pada sektor-sektor penting dan pembiayaan proyek perumahan.

5. Berdasarkan nilai maghashid syariah Imam Al Syathibi yang ke-2 dan ke-3, bahwasanya haruslah berilmu dan ilmu itu harus di aplikasikan dalam dunia real maka haruslah ada penyebaran pengetahuan dan keterampilan serta menanamkannya kedalam nilai-nilai individu untuk perkembangan spiritualnya. Dengan demikian, Bank Syariah harus merancang program-program pendidikan dan pelatihan yang harus dapat mengembangkan tenaga kerja berpengetahuan dan terampil serta memiliki nilai-nilai moral yang tepat. Selain itu Bank Syariah juga harus memberikan informasi tentang produk-produk mereka kepada para pemegang saham

\section{DAFTAR PUSTAKA}

Aam Slamet Rusyidiana, Oktober 2016, "Analisis Masalah

Pengembangan Perbankan Syariah Di Indonesia: Aplikasi Metode Analytic Network Process", Jurnal Bisnis Dan Manajemen, Volume 6 (2).

Abdul Jabbar Bin Ahmad Bin Abdul Jabbar Al Qadhi Abul Hasan Hamdani, 1996 M, 1416 H,

Syarah Ushul Khamsah, (Cairo: Maktabah Wahbah).

Abdul Karim Bin Muhammad Bin Manshur As Sam'ani, $1382 \mathrm{H}$, 1962 M, Al Ansaab, (Ahidar Abad: Majlis Daerah Al Ma'arif Al Ustmaiyah).

Abdullah Saeed, 2003, Bank Islam Dan Bunga Bank, Studi Kritis Dan Interpretasi Kontemporer Tentang Riba Dan Bunga, (Yogyakarta: Pustaka Pelajar).

Abu Ishaq As Syatibi, 2006, Al Muwafaqaat Fi Ushulissyari'ah, (Kairo: Maktabah Al Usrah).

Aj Jauhary, Asshhah Tajullughah Wa Shahhah Al Arabiah Tahqiq Ahmad Abdul Ghafur

Departemen Agama R.I, 2004, AlQur'an Dan Terjemahnya. Jakarta: CV Naladana.

Djazuli,A. Kaidah-Kaidah Fikih: Kaidah-Kaidah Hukum Islam Dalam. 
Dr. Abdur Razaq Waraqyah, June 2007 M, Jamada II $1428 \mathrm{H}$, Maslak Al Imam Al-Syathibi Fi Taq'id Al Maqashid Watanziil Ahkam, Journal Of Sharia And Islamic Studies University of Kuwait, Volume 22, Issue No 69, Kuwait.

Fazlurrahman, 1984, Islam. Transleter Ahsi Bandung: Pustaka.

Http://Kunakaabir.Blogspot.Co.Id/2007/ 09/Imam-Syatibi.Html.

Ibn Manzur. Lisan Al-'Arab, Juz VIII. Bayrut: Dar Al-Sadr, [T.Th.].

Jumansyah, Ade Wirman Syafei, Maret 2013, "Analisis Penerapan Good Governance Business Syariah Dan Pencapaian Maqashid Shariah Bank Syariah Di Indonesia", Jurnal Al-Azhar Indonesia Seri Pranata Sosial, Vol . 2, No. 1.

La Jamaa, Juli-Desember 2011, “Dimensi Ilahi Dandimensi Insani Dalam Maqashid Al-Syari'ah", AsySyir'ah Jurnal Ilmu Syari'ah Dan Hukum, Vol. 45 No. II.

Muhammad Bin Ahmad Arromli Al Anshori, 1994 M, 1414 H, Ghayatul Bayan Syarah Zabad Ibnu Ruslan, (Beirut: Dar Ma'rifah).

Muhammad Syafii Antonio, Yulizar D. Sanrego, Muhammad Taufiq, (2012), "An Analysis Of Islamic Banking Performance: Maqashid Index Implementation In Indonesia And Jordania", Journal Of Islamic Finance, Vol. 1 No. 1, 012 - 029. IIUM Institute Of Islamic Banking And Finance ISSN 2289-2117 (O) / 2289-2109 (P)

Muhammad Zaki, Bayu Tri Cahya, Desember 2015, Aplikasi Maqasid Asy-Syari'Ah Pada Sistem Keuangan Syariah, Jurnal Bisnis Dan Manajemen Islam, BISNIS, Vol. 3, No. 2.
Sepky Mardian, 2015, “Tingkat Kepatuhan Syariah Di Lembaga Keuangan Syariah", Jurnal Akuntansi Dan Keuangan Islam

Syaltut, Mahmud. 1966, Islam: 'Aqidah Wa Syari'ah. Kairo: Dar AlQalam,.

Syarifuddin, Amir, 1999, Ushul Fiqh, Jilid 2. Cet. I; Jakarta: PT Logos Wacana Ilmu.

Syihabuddin Abi Abdillah Yaqut Bin Abdillah Al Hamawi Ar Rumi, 1977 M, 1397 H, Mu'jam Al Buldan, (Beirut: Dar As Shadir).

Tempo.Co, 2018, 7 Masalah Bank Syariah, Https://Bisnis.Tempo.Co/Read/7 21104/Ini-7-Masalah-BankSyariah, Pada Tanggal 30 Januari, Jam 22:52 